\title{
Exploring ICT practices through Echo 360
}

\author{
Kwong Nui Sim \\ Victoria University of Wellington \\ Wellington, New Zealand
}

\begin{abstract}
This paper reports the findings from a pilot study that investigated the use, by two learning and teaching technologists, of Information and Communication Technology (ICT), an automated lecture-capture system (Echo 360), to support their daily practices. Data sources included computer activity records extracted from the participants' computers at their work areas via the use of Echo 360. Data were analysed using an interpretive approach resulting in three themes: (a) the advantages and the strengths of using screen capture (or 'screencasting') as a method in research; (b) the notion of 'multitasking' in the process of ICT use; (c) the understanding of 'human-computer' interaction in today's higher education. Through monitoring the navigation of the users' actions within the computers' interfaces in real time, the screen capture provided an accurate account of how participants used their computer technologies and what they were doing with them. The screen capture data revealed the sense of 'digital literacy' among the participants and the findings therefore provided insights into ideas about how to develop a more structural ICT support system for academic teaching staff. Such support would be beneficial to promote the use of ICT among academic teaching staff in the processes of teaching, learning and researching. The findings of this study, however, raised questions about the role played by technologies in advancing the research in higher education, and they highlighted a possible limitation in academic-orientated use of computer technologies by academic teaching staff. In short, this pilot study is framed by the question "How do the assumptions and expectations of technologies' use held by academic teaching staff influence their daily practice, and vice versa?"
\end{abstract}

Keywords: academic practices; actual practice data; ICT; perception data; screen capture.

\section{Introduction}

Over the past decade, higher education has come under increasing pressure to embrace the opportunities presented in the now-pervasive and sophisticated world of ICT (Aviles, Philips, Rosenblatt, \& Vargas, 2005; Farrington \& Yoshida, 2000; Gonick, 2002; Nijenga \& Fourie, 2010). ICT refers to information 
technology in the context of the integration of telecommunications, computers, software, and the data systems that support, store, and transmit unified communication technologies, for users to access and manipulate information (Murray, 2011). Much of this pressure comes from the belief that ICT can change or even improve the way students study and engage in higher education. Certainly, the use of ICT to support teaching and learning has received considerable attention in recent years (Sharma, 2010), with many researchers agreeing that "there is a common trend toward improving learning through a seamless integration of technology" and that "students learning in the modern technology era are highly competent in general computer skills and are more prepared to learn with technology" (Keengwe, 2007, p. $177 \&$ 178). In other words, access to a range of ICT, such as desktops, laptops, smart phones, and tablets enables users to capture, share, collaborate and publish in previously unavailable ways.

\section{Background}

The aim of this paper is not to continue the debate on whether ICT in higher education is essential, detrimental, neutral or beneficial to student learning, but to investigate a method that examines the degree to which academic teaching staff actually use their computers to support their daily academic practices. The focus is to investigate the ways ICT could be adopted to capture academic teaching staff's use of ICT in their daily academic practices. This is particularly in the sense of 'digital competence' and 'digital confidence' among the academic teaching staff as well as insights into ideas about how to develop a more structured ICT support system for academic teaching staff, should it be needed.

Recent publications that have reported on the methods used to research this topic reveal that most empirical research on the use of ICT in higher education is based on self-reports of use (Edmunds, Thorpe, \& Conole, 2012; Park, 2009), which mainly involve questionnaires or interviews. It is this paper's contention that such findings, while relevant to explorations of perceptions or post-event recollections of ICT use, fail to offer an objective picture of actual practice. For this reason, the data gathered for this pilot study was gained from an experiment capturing actual computer use obtained through software that is already provided on every staff member's computer within a particular university in New Zealand.

The primary question that can be asked from this study is whether there is a difference between academic teaching staff's perceptions and practices in relation to their ICT use. The sub-questions are: If there is a difference, how valid is perception data, especially in terms of understanding academic teaching staff's ICT use? Even if there is no difference, how do expectations and assumptions about the role of ICT influence academic teaching staff's use of ICT in their daily academic practices, and how do the academic teaching staff's practices inform their perspectives about ICT use?

ICTs have become increasingly common in higher education, especially in academic teaching staff's research practice, so it is worthwhile to determine the 
significance of ICT in their practice. It would be fair to say that academic teaching staff are thinking about the degree to which they are using ICT daily for their teaching, learning and research practices in this time of accelerated change (New Zealand Productivity Commission, 2016). This proposed study thus sought to examine how academic teaching staff use ICT to support and advance their academic practices in the process of teaching, learning and researching, by looking at the ways they use their various ICT devices and applications for academic purposes through practice data.

\section{Method}

Reflecting on the research question of whether there is a difference between academic teaching staff's perceptions and practices in relation to their ICT use, the methods employed in this pilot study were based on the intention to solve a "puzzle" in relation to a particular context. Two data collection methods were used to achieve the aim of the research, which was to investigate the beliefs and practices related to ICT use held by academic teaching staff at a public university in New Zealand. Computer activity data was gathered using a software programme, Echo 360 (a built-in automated lecture capture system in the university, known as Vstream), that captures computer activities as well as the behaviours that were shown while using computers. The computer activity data recorded the types of programmes as well as the websites visited. This included dates/times and durations as well as the user's behaviours as reflected in their ICT practices. In other words, Echo 360 provides the ability of screen capture ("screen casting"). At the same time, the discussion data was used to gain insights into the participants' expectations and assumptions about ICT use in their daily academic practices.

Given the exploratory nature of this pilot study, two learning and research technologists (the professional staff who works the closest with academic teaching staff), Lucas and Suzanna (pseudonyms), volunteered to be the participants for this purpose (see Figures 1 and 2 below). Both of them chose a random day respectively and recorded their computer activities at work through Echo 360. The study adopted the interpretive, naturalist enquiry approach of Guba and Lincoln (1989), and the analysis approach of Constructivist Grounded Theory of Kathy Charmaz (2006). Charmaz (2006) emphasised this flexibility and viewed Grounded Theory as a set of principles and practices. She focused on examining data, making the study action-centred, and interpreting the data. For her, no data or theory could be discovered, as grounded theories are constructed through our constant interactions with others. The Constructivist Grounded Theory approach was used, based on an emergent design (Cavallo, 2000), which aimed to capture the emergent phenomena that were important to understand, within the scope of this pilot study. This study did not aim to capture a single reality or truth. Rather, it aimed to construct "images of reality" (Charmaz, 2000, p. 523), by including multiple perspectives.

Further, the Constructivist Grounded Theory approach underpins the decision for the selection of a small number within a particular context to understand their experiences rather than a focus on generalisable findings. Throughout the 
process of the pilot study, there was raised awareness of the possibility of more than one analytic direction. The single events that occurred throughout the process, were viewed as possible contributing parts of a larger whole at the end of the process

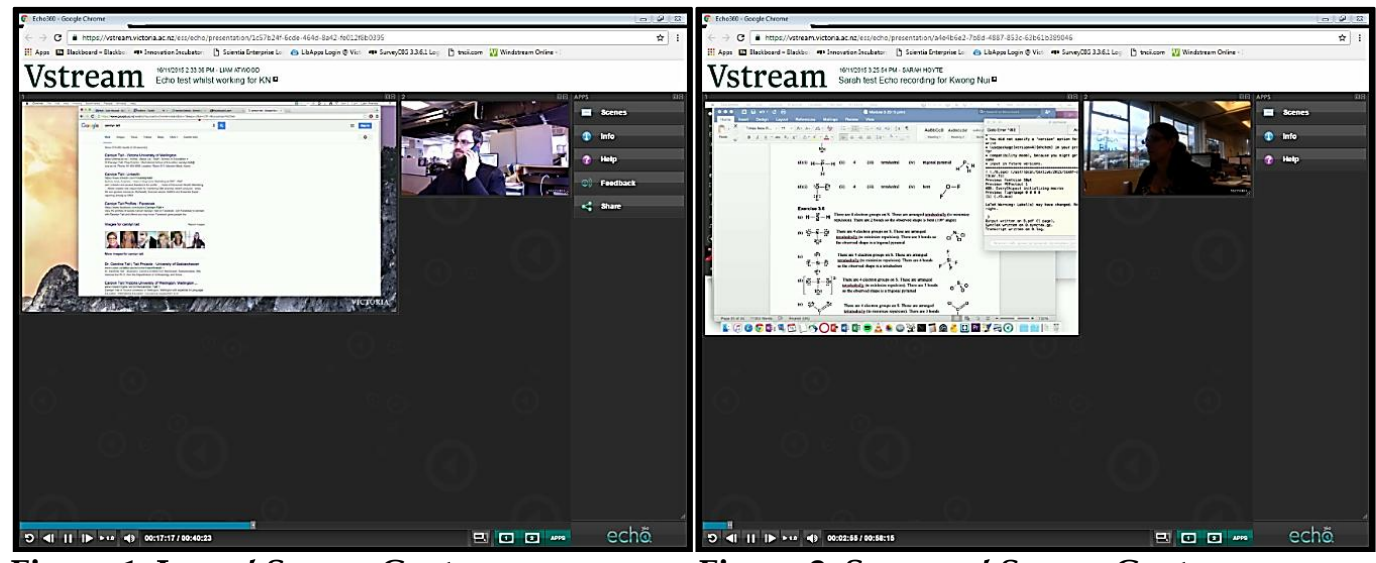

Figure 1: Lucas' Screen Capture.

Figure 2: Suzanna' Screen Capture.

The nature of the Constructivist Grounded Theory approach meant that there was a consequent overlap between the data collection and the data analysis phases: iterative processes of reviewing data collection method/type occurred alongside the emergence of findings and the development of themes wherein hypotheses emerged or unfold from interactions between the data, the actions, and the perspectives of the researcher and the participants. The researcher's active discovery played a significant role in constructing themes from analysing data. The careful and precise application of Constructivist Grounded Theory ensured that the ideas which emerged from this study were rigorous and verified. It was a process of reality construction that offered a comprehensive framework (including the analysis of the process), acknowledged macroscopic issues related to the phenomenon under investigation, and acted as a precursor for further study in limited research areas (Charmaz, 2006). Thus, the analysis in this pilot study attended to what was being heard, seen and sensed and pursued potential analytic ideas about the study as a consequence.

Because each participant was recognised as an independent source of evidence, a case study approach was adopted. A case study is both a process of inquiry about a case and the result of that inquiry (Stake, 2000). It is believed to be one of the preferred ways of doing research using Grounded Theory (Lehmann, 2001; Maznevski \& Chudoba, 2000; Orlikowski, 1993; Urquhart, 2001), as it will enhance the construction of novel, testable and valid theory (Strauss \& Corbin, 1990). Apart from the participants' ideas, the researcher's viewpoint, as well as the information and the "degree of sophistication available" (Guba \& Lincoln, 2001, p. 7) served as variable and transformable knowledge. Accepting this coconstruction, data were placed into their relevant situational and social contexts, according to the emergent themes as interpreted by the researcher. As concluded by Campbell (2011), a theory is grounded in the research data when there is a constant iterative proposing and checking process within the scope of this pilot 
study, such that the theory is not applied to the data, but the data generates the theory.

\section{Findings}

Guided by the core areas of interest, an analysis of the computer activities data in relation to the discussion data using the coding processes of constructivist grounded theory as mentioned above, resulted in three themes:

- The Method

- $\quad$ The Notion of 'Multitasking'

- 'Human-Computer' Interaction

The Method: Screen capture reveals a participant's actual use of computer in the light of his/her perspectives of an on-screen experience. It captures what is happening on a particular screen of a computer system at a real time and records it as a video file which can be accessed at any time later. It also provides an opportunity for the participants to optionally record themselves from the webcam, which synchronously records to the screen capture file and the recording is either embedded within it or provided in a second stream. At the same time, it allows recording of the microphone input on the computer and detects whatever is heard by this source, whether it be the ambient noise or the narration of the participant. It is interesting to discover that the participants selfnarrated what they were doing at times when they were using their computer. In short, such data collection method produces a rich data source, which presents moment-by-moment on-screen phenomena at a real-time computer activity process. Specifically, it allows the researcher to see the navigation of the participant and his/her actions within the computer interface.

The Notion of 'Multi-tasking': The computer activities data via screen capture showed that both Lucas and Suzanna had a high tendency of 'multitasking' at all times. This aligns with the studies which describe how the present generation of students "multi-task" with ICT (e.g., Zhang, Sun, Chai, \& Aghajan, 2015) even though the idea of multi-tasking has been critiqued in the existing literature (e.g., Sana, Weston, \& Cepeda, 2012). For example, Lucas played an online game as well as checked and replied to his emails intermittently while working on some technological requests for a course (see Figure 3 below). As for Suzanna, she searched images on Google and did calculations on the Calculator while trying to design a module for a course (see Figure 4 below). It is worth noting that both the technologists did not use a dual screen (even though it is provided for them) despite their ongoing multi-tasking mode and their notion of multitasking consists of Internet use at all times. Perhaps this aligns with the statement made by Lieutenant Colonel Greg Conti, the director of West Point's Information Technology Operations Centre (Economist Intelligence Unit, 2008), "it is impossible to sit someone in front of the World Wide Web and expect them not to use it" in today's world because "[today people] are used to getting what they need instantly" (p. 12). It is believed therefore, that in time, as new technologies are introduced and embedded into life more broadly, ICT will become even more interwoven into academic teaching staff life in general. 


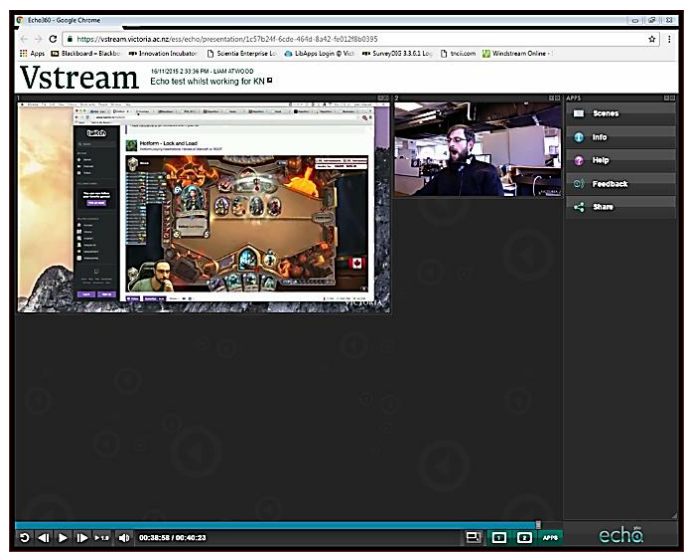

Figure 3: Lucas' Gaming Scene.

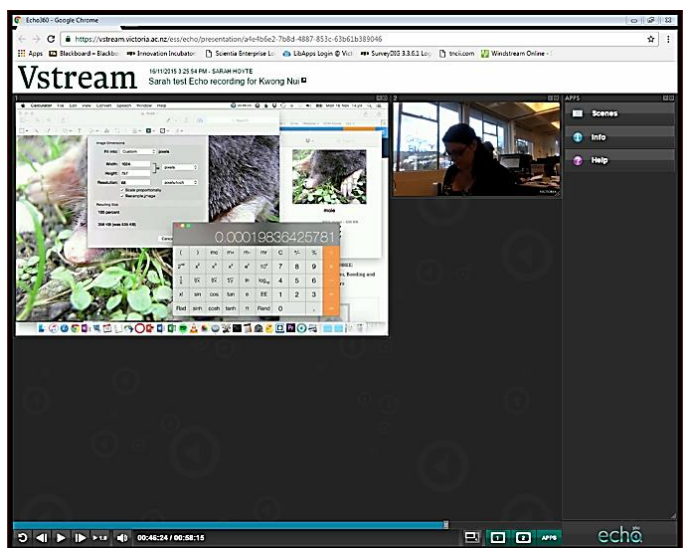

Figure 4: Suzanna' Multiple Windows.

'Human-Computer' Interaction: Because of the screen capture method, there is an advantage of getting an idea of what the researcher is seeing and hearing (optional) when the participants were working on their computer through screen capture at the real time. This optional audio data has some benefits, in particular if the consumption of media is being studied as part of 'human-computer' interaction; otherwise, it is relatively supplementary to the process and it is always optional to being used, subject to the participants' consent. Also, a good understanding of the participant's ICT experience is gained by examining the expressions and gestures of the participants (see Figures 5 and 6 below) when using ICT without intrusion of the researcher in the situated context. Such 'human-computer' interaction embedded within the screen capture data exposes the component of actual practices and in-moment reflection. Later, participants were asked to reflect upon or justify why they had completed a certain action. This provided additional data alongside the real time screen recording and offered a more in-depth analysis of ICT practices.

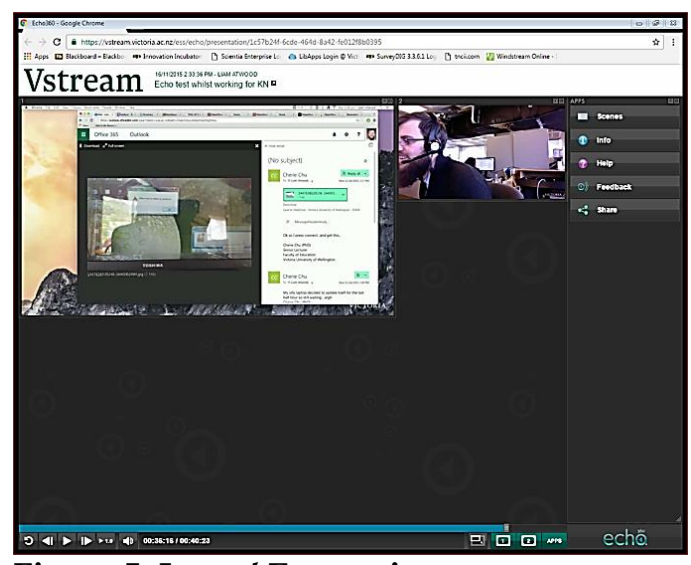

Figure 5: Lucas' Expressions.

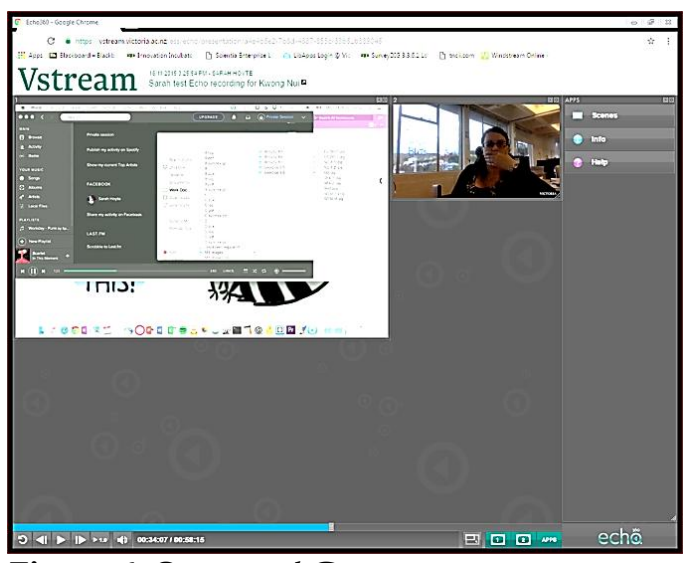

Figure 6: Suzanna' Gestures. 


\section{Discussion}

The initial interest of this pilot study was to examine the degree to which academic teaching staff use their personal computers to support their daily academic practice. With a guaranteed working space with computer devices and having access to Internet, the researcher was curious to know how academic teaching staff were actually using them to support their process of teaching and learning as well as researching.

While this seems a rather unassuming project at the outset, difficulties soon arose regarding definitions of what constituted valuable and reliable data. Much of the literature on the place of ICT in supporting higher education is based on perception data and/or post-event recollections of behaviour. It bothered the researcher that many of the claims concerning behaviour were based on selfreported or observed perspectives by researchers or others at a certain moment of time. It was particularly disconcerting to notice how authors often subconsciously moved to asserting findings as if they represented actual behaviour. The researcher became convinced that post-event recollections and perceptions were not a valid way to represent actual data. For this reason, the researcher investigated a range of possible ways to gather naturally occurring data. Clearly, the ability to track computer activities as they happened seemed the most obvious. Tracking actual computer use in this way offers an opportunity to capture actual computer usage data. The researcher can access the naturally occurring computer activity which gives a way of 'seeing' what participants did (and did not do) rather than what they said they did or did not do.

In addition, higher education has come under increasing pressure to embrace the opportunities presented in the now pervasive and sophisticated world of ICT. ICT use to support teaching and learning as well as researching, has thus received considerable attention in recent years (e.g., Aspden \& Thorpe, 2009; Henderson, Selwyn, Finger, \& Aston, 2015). The findings of this study, however, raised questions about the role played by ICT in advancing academic practices in higher education and highlighted an aspect of possible limitations in academicorientated use of computer technologies (e.g., the use of a dual screen) by staff members. It would be fair to say that academic teaching staff or the university staff members (i.e., the technologists) understand the importance of producing quality work and that they engage in every effort to achieve. The predominant message regarding ICT use is that the more it is used, the more likely one will see benefits in terms of productivity, efficiency and quality. This could indicate that explicit ICT support could be embedded into academic teaching staff's practices in order to develop 'digital competence' and 'digital confidence' or even 'a digital comfort zone' among the academic teaching staff and university staff members. While it is acknowledged that adaptation takes time, it is important for academic teaching staff as well as technologists in this case, who are at an advanced academic level, to continually review, revise, and improve their academic practices based upon current and anticipated future needs.

Further, it is suggested that the academic teaching staff need to look beyond their own experiences and promote ICT use actively. The diverse perspectives on efficiency and effectiveness in ICT use held by the participants could be barriers 
for optimal use of ICT. The findings imply that the ways participants choose to use ICT is based on their perception of being effective and efficient. But when certain types of applications or use of ICT are commonly agreed upon, they become a norm, in the same way as multi-tasking and multiple windows are used simultaneously. Therefore, in order to achieve this shared sense of ICT use, institutions could articulate a vision about the role of ICT, and ensure that the vision is communicated clearly and embedded in institutional practices. Part of such a vision would be to emphasise the need to focus on the process of supporting and enhancing ICT use in the light of academic practices.

Lastly, for the question "How do the assumptions and expectations of technologies' use held by academic teaching staff influence their daily practice, and vice versa?", the findings in this pilot study suggested that the participants' perspectives and behaviours of ICT use are pre-determined by the 'norms' within their context. It seems that the participants are competent and confident of their ICT use in their daily practice but they were not aware of the actual extent of the use. This pilot study raised their awareness of this and hence, there could be a strong possibility, if opportunities are made available for academic teaching staff, they would be able to experience a kind of "educational technological transformation" within their daily academic practices at the university. This may be particularly possible when the actual behaviours are exposed to them through studies such as this on, so that their overlooked or taken-for-granted behaviours are made explicit. Such exposure is significant in supporting the academic teaching staff to improve the use of ICT for education/teaching and learning process as well as to drive for meaningful changes in their daily academic practices (Costley, 2016).

\section{Conclusion}

Involving a small cohort of participants who are not actually academic teaching staff and only focussing on one day of use of ICT as represented in this pilot study could be seen as limitations to the research. However, the small number of participants and the much-focussed concentration on ICT practices enabled a deep analysis to be undertaken within that context. The research design and the methodological foundations of this study aligned well with the size and nature of the investigation. Studying ICT in these directions could offer fresh perspectives and opportunities to think differently and reveal new ways to research ICT. These will provide an active way of understanding the phrase, "the role of ICT in higher education"; that possible social accounts emphasise how academic teaching staff (technologists in this case) are not simply caused to act by ICT, but are wellpositioned to make sense of ICT and integrate ICT meaningfully into academic practices in an active way and, through doing so, embed the role of ICT in higher education. As evidenced from the findings in this pilot study, the participants were not aware of the extent of their use of ICT in their daily academic practices despite the nature of their job. The study raised their awareness of this (e.g., the multitasking and the human-computer interaction) through screen capture; however, this newly gained awareness did not appear to change the participants' behaviour dramatically. It did provide a degree of self-awareness about their computer usage thought. Such an unexpected outcome from the study reveals that 
there could be a strong possibility, if opportunities are made available, for academic teaching staff to experience a kind of "education technological transformation" within their academic practices at the university. This may be particularly possible when the academic teaching staff's behaviours are exposed to them through studies such as this one, so that their overlooked or taken-forgranted behaviours are made explicit. The different involvement, interactions, and perspectives between the past and present, before and after taking part in a study like this one, could lead the academic teaching staff to re-reflect on, or even change, their practices.

In summary, this pilot study provided an opportunity to review the idea of using technology to capture the use of computer technologies (practice data) at a real time in order to open a space for nurturing the development of 'digital research'. Perhaps studies on larger scale of data and the involvement of actual academic teaching staff group could be considered in order to obtain more representative data of the ICT use for academic practices.

\section{Acknowledgements}

To Liam Atwood and Sarah Hoyte, the learning and research technologists, for their contribution to this pilot study.

Part of the idea from this pilot study was presented at the Tertiary Education Research in New Zealand (TERNZ) Conference in November 2016 at Dunedin, New Zealand.

\section{References}

Aspden, E. J., \& Thorpe, L. (2009). "Where do you learn?": Tweeting to inform learning space development. Retrieved from http:/ / www.educause.edu/ero/article/where-do-you-learn-tweeting-informlearning-space-development

Aviles, K., Philips, B., Rosenblatt, T., \& Vargas, J. (2005). If higher education listened to me. Educause, 7.

Campbell, J. (Producer). (2011, 4th January). 38. Introduction to methods of qualitative research grounded theory. Retrieved from http:/ / www.youtube.com/watch?v=kOLBtUiSCwY

Cavallo, D. (2000). Emergent design and learning environments: Building on indigenous knowledge. IBM Systems Journal, 39(3 \& 4), 768-781.

Charmaz, K. (2000). Grounded theory. Objectivist and constructivist methods. Thousand Oaks, CA: Sage.

Charmaz, K. (2006). Constructing grounded theory: A practical guide through qualitative analysis. Thousand Oaks, CA: Sage.

Costley, J. (2016). The Importance of Educational Technology to Pedagogy: The Relevance of Dewey. International Journal of Learning, Teaching and Educational Research, 15(8).

Economist Intelligence Unit. (2008). The future of higher education: How technology will shape learning. Retrieved from 
Edmunds, R., Thorpe, M., \& Conole, G. (2012). Student attitudes towards and use of ICT in course study, work and social activity: A technology acceptance model approach. British Journal of Educational Technology, 43(1), 71-84. doi:10.1111/j.1467-8535.2010.01142.x

Farrington, G. C., \& Yoshida, R. K. (2000). Darwin educational competition in the dot com world Educause, 6.

Gonick, L. (2002). A new role. Educause, 2.

Guba, E. G., \& Lincoln, Y. S. (1989). Fourth generation evaluation. Newbury Park, Ca: Sage.

Guba, E. G., \& Lincoln, Y. S. (2001). Guidelines and checklist for constructivist (a.k.a. fourth generation) evaluation. Evaluation Checklists Project, 1-15.

Henderson, M., Selwyn, N., Finger, G., \& Aston, R. (2015). Students' everyday engagement with digital technology in university: exploring patterns of use and 'usefulness'. Journal of Higher Education Policy and Management, 37(3), 37-41.

Keengwe, J. (2007). Faculty integration of technology into instruction and students' perceptions of computer technology to improve student learning. Journal of information technology education, 6, 169-180.

Lehmann, H. P. (2001). Using grounded theory with technology cases: Distilling critical theory from a multinational information systems development. Journal of Global Information Technology Management, 4, 45-60.

Maznevski, M. L., \& Chudoba, K. M. (2000). Bridging space over time: Global virtual team dynamics and effectiveness. Organization Science, 11(5), 473-492.

Murray, J. (2011, December 2011). Cloud network architecture and ICT. Retrieved from http://itknowledgeexchange.techtarget.com/modern-networkarchitecture/cloud-network-architecture-and-ict/

New Zealand Productivity Commission. (2016). New Models of Tertiary Education. Retrieved from www.productivity.govt.nz/inquiry-content-tertiary-education

Nijenga, J. K., \& Fourie, L. C. H. (2010). The myths about e-learning in higher education. British Journal of Educational Technology, 41(2), 199-212.

Orlikowski, W. J. (1993). CASE tools as organizational change: Investigating incremental and radical changes in systems development. MIS Quarterly, 17(3), 309-340.

Park, S. Y. (2009). An analysis of the technology acceptance model in understanding university students' behavioral intention to use e-Learning. International Forum of Educational Technology \& Society (IFETS), 12, 150-162.

Sana, F., Weston, T., \& Cepeda, N. (2012). Laptop multitasking hinders classroom learning for both users and nearby peers. Computers \& Education, 62, 24-31.

Sharma, V. (2010). The effect of IT based learning on human values of students undergoing higher education. International Transactions in Humanities \& Social Sciences, 2(2), 283-287.

Stake, R. E. (2000). Case Studies (Second ed.). Thousand Oaks: Sage Publications, Inc.

Strauss, A., \& Corbin, J. (1990). Basics of qualitative research : Grounded theory procedures and techniques: Newbury Park, Calif. : Sage Publications.

Urquhart, C. (2001). An encounter with grounded theory: Tackling the practical and philosophical issues (E. Trauth Ed.). PA, USA: IGI Publishing Hershey

Zhang, T., Sun, X., Chai, Y., \& Aghajan, H. (2015). A look at task-switching and multitasking behaviors: From the perspective of the computer usage among a large number of people. Computers in human behavior, 49, 237-244. 